\title{
Stealing their beer time: turning studying for medical progress tests into a game
}

\author{
Aletta Smits ${ }^{1}$, Annette Schenk ${ }^{1}$, Lizet van Ewijk ${ }^{1}$ \\ ${ }^{1} \mathrm{HU}$ University of Applied Sciences Utrecht, The Netherlands.
}

\begin{abstract}
Many health education programs use progress tests to evaluate students' progress in learning and to identify possible gaps in the curricula. The tests are typically longitudinal and feedback-oriented. Although many benefits of the progress test have been described in the literature, we argue that the acclaimed facilitation of deeper learning and better retention of knowledge appear questionable. We therefore propose an innovative way of presenting both the test itself and the study process for the test: a real-time-strategy game with in-game challenges, both individual and in teams. In this conceptual paper we provide a brief overview of the benefits and challenges of progress testing and illustrate how gamifying the process of both the assessment and preparatory work taps into many aspects that educators would like to promote in their students' learning outcomes and behavior. We then argue why and how we aim to create a pilot version of a progress test game for medical and allied health students. For the development of this game, six tracks are proposed, that will run mostly in parallel in an iterative process, using design-based research as a framework.
\end{abstract}

Keywords: progress tests; gamification; allied health; education. 


\section{Introduction}

Because of the specific requirements of the (allied) health professions, it is imperative that clinicians-to-be have a wide range of knowledge at their fingertips (Dijksterhuis, 2014). To facilitate this, most health education programs employ a type of overall ready-knowledge test: a test that is not connected to one specific course but contains questions on all the facts and figures from all courses in the curriculum, a so-called progress test (Scheele et al., 2004). Although many benefits of the progress test have been described in the literature, we will illustrate in section 2 that the acclaimed facilitation of deeper learning and better retention of knowledge appear questionable. We therefore propose an innovative way of presenting both the test itself and the study process for the test: an online real-time-strategy game with ingame challenges, for both individals and teams. The game will be embedded in the social context of a program in order to induce an online and offline spectator experience along with the gaming experience. The game should be developed in such a way that the best parts of gaming (as a player and as a spectator) meet the characteristics we would like a student to display in his or her studying behavior. The result should be a student who enjoys spending more time-on-task and more academic learning time (Chickering \& Gamson, 1987).

\section{Progress tests in medical and allied health education}

Progress testing was introduced in the 90 s in the Netherlands. Since the tests include items from all relevant disciplines in a curriculum, they are comprehensive and mainly contain multiple choice questions. The tests are administered repeatedly to learners at different stages in their training in order to monitor their progress (Bolhuis, 2005, Dijksterhuis, 2014). In the medical programs in The Netherlands, for example, the progress test is administered between one and four times per year to all students participating in the program (Freeman et al., 2010, Dijksterhuis, 2014). First year students are required to answer the same questions as fourth year students. However, for first year students the thresh hold for passing the exam is at a lower level.

\subsection{Progress tests; benefits and challenges}

Progress tests have many benefits from an educators' point of view: they allow for early identification of high achievers, can be used to chart growth of knowledge and clinical skills, possibly remove the need for resits and provide an excellent benchmark to compare performance across programs (Pughet et al. 2015; Freeman et al., 2010). Criticism from within the medical community on the lack of generalisability of the competencies to clinical reasoning in uncertain, realistic contexts, has been addressed by adding open questions to the test. Recently, script concordance testing (Charlin et al., 2000), a scenario-based way of 
testing how students apply knowledge in practical situation, has been suggested as the possible next version of the progress test.

Furthermore, progress tests have been argued to have tangible benefits beyond those of simply measuring progress. Coombes et al. (2010) show that progress tests allow for the provision of feedback and therefore should aid learning. Performance can be reviewed by students online, by means of percentages for the different categories within the test. This allows the student to identify areas of weakness they will need to improve on. Further benefits to learning have been proposed by Pugh and Regehr (2016), who suggest that progress tests encourage continuous studying over cramming and therefore foster deep learning strategies and better retention of knowledge.

A study amongst over 6000 Dutch medical students (Dekker \& de Feijter, 2007), however, contradicts this assumption. While students appreciate the test because of the sense of progress it provides to them, they widely report that for this test, too, they prepare in cramming sessions (cf. Dijksterhuis, 2014). Furthermore, despite the possibility of receiving feedback, $78 \%$ of students report that they do not revise the content of the categories that they scored poorly on. In fact, earlier research shows that just under half of the students does not even log in to view their feedback (Thoben et al., 2006). Therefore, despite the noble intentions of the progress test, its goals are not entirely achieved: educators need to devise a way to make studying for the test more challenging, with more direct feedback, to keep students interested. We propose a game.

\section{Why we play games and why playing games is a good thing}

\subsection{Why we play games}

Video game players report that playing a game can bring them in a state of immersion or even flow (Brockmyer et al., 2009). Flow is described as the joy a person experiences when "a balance between skill and challenge is achieved in the process of performing an intrinsically rewarding activity". Flow is increased by "the presence of a specific goal and an immediate performance feedback structure" (Moneta \& Csikszentmihalyi, 1996). It is suggested that being in a flow enhances learning. It entails a feeling of being in control, being one with the activity, and experiencing time distortions (Coller \& Shernoff, 2009).

This is exactly the purpose of our proposal: to turn studying for this test into something that brings students in a state of flow. In order to achieve this, the test should integrate: a balance between skill and challenge; an environment that students feel part of; and an immediate feedback process that helps them learn. That is part I of 'stealing their beer time': time they normally spend on 'going out' is now spent on doing something else fun, namely studying for their test. Part II of 'beer time stealing' will be discussed in section 4. 


\subsection{Why playing games is good}

Games - well-designed games that match with the target group - are not only an engaging activity that can bring its players in a state of flow. It has been shown extensively that the process of becoming good at a game involves many aspects that educators would like to promote in their students' learning outcomes and behavior. In a meta-study, Hainey et al. (2011) found that playing games resulted in better developed long-term and short-term memory, faster perception of a pattern, improved qualitative thinking, and principled decision-making and self-observation. Coller \& Shernoff (2009), furthermore, state that learning principles in video games match with constructivist learning theories, active learning, and metacognition. Finally, multiple studies have shown students playing on-topic video games are considerably more engaged, exhibit dramatically better learning outcomes (Coller \& Scott, 2009), demonstrate deeper learning, and spend more time on their course than students who study in the classic way (Coller \& Shernoff, 2009, Koivisto \& Hamari, 2017, Legaki et al., 2019). Specifically for medical education Mayo (2009) reports that a gamified version of teaching immunology can yield a $7 \%$ to $40 \%$ increase in learner outcomes but warns that such positive effects are only inspired by well-designed games.

We will as a result attempt to change the way the students prepare for their progress test by gamifying their process of studying.

\section{Turning gaming into a spectator sport}

We propose to take the process one step further: we intend to design not just a good game, but also create an environment in which playing the game can be followed by spectators, both online and offline. This is where we touch upon part II of 'stealing their beer time'.

It has been shown multiple times that being a spectator at a sport, be it a physical sport or a game, improves motor skills (model learning, cf. Giudice, Manera, \& Keysers, 2009). This is the main reason for attempting to steal students' beer time in this particular way: if we can turn students into spectators of the 'school game', not just the players but also the audience will improve their skills. As a result, they will learn more and/or enjoy playing more (increased time-on-task). Specifically for video games, this is further facilitated by the interactive nature of streaming platforms (Sjöblom \& Hamari, 2017).

A second reason for using the spectator element is to create a community around this game. Watching events together supports a feeling of belonging (Sjöblom \& Hamari, 2017). This feeling of 'being part of a group', being inside the magic circle (Salen \& Zimmerman, 2003), facilitates social integration, an aspect that has repeatedly been shown to be an important factor promoting student success (Tinto, 1987). It is, therefore, imperative to design not just the game, but also the gaming context: public challenges, leader boards, etc. 


\section{Turning an assessment into a game}

As we have seen above, the goals of the progress test do not differ much from the strategies students naturally employ when becoming good at a video game. Playing an on-topic video game, that is designed with careful regard for game play, game rules and game world (Aarseth, 2003), will therefore undoubtedly promote the behavior in clinicians-to-be that the progress tests already try to illicit (Mayo, 2009).

While the feedback provided by the progress test is typically not consulted by the average student, the feedback in a video game is more immediate and more to the point: it helps to reach the immediate goal (continuous immediate feedback), and will also dole out immediate rewards (positive reward system in the form of badges, XPs, accessories, etc.). Rather than losing points for incorrect answers, students gains levels/XP/avatar strength whenever (s)he masters a specific topic, or nails a series of questions on different topics within a specific time frame ('challenge'). Whilst a progress test that is designed for final year students might make a first year student feel little in control, a video game allows the opportunity for adaptive learning (just in time information) and the opportunity to process increasingly complex information in increasingly complex contexts (concurrence chaining). This last element also connects well with the scenario based testing that medical programs are now experimenting with (Charlin et al., 2000). Finally, multiplayer strategy games, including individual and team challenges, embedded in the social context of the school, with public battles in the cafetaria, etc., strengthen the social surroundings and facilitate team work.

\section{The six tracks in the development process}

The goal of this initiative is therefore to create a pilot version of a progress test game for (allied) health students. Six tracks will be pursued running in parallel in an iterative process, using a design-based research approach (Dolmans \& Tigelaar, 2012). The game play and game structure on the one hand, and the game world (various templates for various programs) on the other hand, are the first two important aspects of this project. A third track will be the distribution of knowledge in the game and the way topics are reintroduced or combined with other topics. This entails collecting content and developing algorithms that facilitate adaptive and non-repetitive presentation of content. A fourth aspect involves the embedding of the game in a social context. A fifth track concerns the technical infrastructure, as Mayo (2009) states: educational games often fail because the distribution and accessibility of the game are not up to par, or because the game cannot handle a certain number of players at the same time. Finally, as a sixth track, we intend to implement the pilot game in at least one of the current curricula (Dental Prosthetics and Speech \& Language Therapy). 


\section{References}

Aarseth, E. (2003). Playing Research: Methodological approaches to game analysis. Presented at the MelbourneDAC: The 5th International Digital Arts and Culture Conference, Melbourne. Retrieved from: http://www.bendevane.com/VTA2012/ herrstubbz/wp-content/uploads/2012/01/02.GameApproaches2.pdf.

Brockmyer, J. H., Fox, C. M., Curtiss, K. A., McBroom, E., Burkhart, K. M., \& Pidruzny, J. N. (2009). The development of the Game Engagement Questionnaire: A measure of engagement in video game-playing. Journal of Experimental Social Psychology, 45(4), 624-634. doi: 10.1016/j.jesp.2009.02.016.

Charlin, B., Roy, L., Brailovsky, C., Goulet, F., \& van der Vleuten, C. (2000). The Script Concordance Test: A Tool to Assess the Reflective Clinician. Teaching and Learning in Medicine, 12(4), 189-195. doi: 10.1207/S15328015TLM1204_5.

Cheung, G., \& Huang, J. (2011). Starcraft from the stands. Proceedings of the 2011 Annual Conference on Human Factors in Computing Systems - CHI '11. doi: $0.1145 / 1978942.1979053$.

Chickering, A. W. (1987). Seven Principles for Good Practice in Undergraduate Education. AAHE Bulletin, Z. F. (Gamson), 2-6. Retrieved from: https://files.eric.ed.gov/fulltext/ED282491.pdf.

Coller, B. D., \& Scott, M. J. (2009). Effectiveness of using a video game to teach a course in mechanical engineering. Computers \& Education, 53, 900-912. doi: 10.1016/j.compedu.2009.05.012.

Coller, B., \& Shernoff, D. J. (2009). Video Game-Based Education in Mechanical Engineering: A Look at Student Engagement. International Journal of Engineering Education, 25(2), 308-317. Retrieved from: http://citeseerx.ist.psu.edu/viewdoc/download?doi=10.1.1.555.9454\&rep=rep1\&type= pdf.

Coombes, L., Ricketts, C., Freeman, A., Stratford, J. (2010). Beyond assessment: feedback for individuals and institutions based on the progress test. Medical Teacher, 32(6):48690. doi: 10.3109/0142159X.2010.485652.

Dekker, J.A., \& de Feijter, J. (2008). De voortgangstoets is geliefd, maar belangen lopen uiteen. Medisch Contact, 63(4), 158-159. Retrieved from: https://www.medischcontact.nl/nieuws/laatste-nieuws/artikel/de-voortgangstoets-isgeliefd-1.htm

Dijksterhuis, M.G.K. (2014). De Nederlandse Voortgangstoets Obstetrie en Gynaecologie. Nederlands tijdschrift voor Obstetrie \& Gynaecologie, 127, 90-94. Retrieved from: http://www.ntog.nl/dynamic/media/3/documents/NTOG_2014_2-web.pdf 
Dolmans, D. H. J. M., \& Tigelaar, D. (2012). Building bridges between theory and practice in medical education using a design-based research approach: AMEE Guide No. 60. Medical Teacher, 34(1), 1-10. doi: 10.3109/0142159X.2011.595437.

Duncan, M. C. (1983). The Symbolic Dimensions of Spectator Sport. Quest, 35(1), 29-36. doi: 1080/00336297.1983.10483780.

Freeman, A. van der Vleuten, C., Nouns, Z., and Rickets, C. (2010) Progress testing internationally, Medical Teacher, 32(6), 451-455. doi: 10.3109/0142159X.2010.485231.

Giudice, M. D., Manera, V., \& Keysers, C. (2009). Programmed to learn? The ontogeny of mirror neurons. Developmental Science, 12(2), 350-363. . doi: 10.1111/j.14677687.2008.00783.x.

Hainey, T., Connolly, T., Stansfield, M., \& Boyle, E. (2011). The differences in motivations of online game players and offline game players: A combined analysis of three studies at higher education level. Computers \& Education, 57(4), 2197-2211. doi: 10.1016/j.compedu.2011.06.001.

Legaki, N.Z., Nannan, X., Hamari, J., Vassilios, A. (2019). Gamification of the future: an experiment on gamifying education of forecasting. In: 2019 52th Hawaii international conference on system sciences (HICSS). IEEE. doi: 10.24251/HICSS.2019.219

Mayo, M. J. (2009). Video Games: A Route to Large-Scale STEM Education? Science, 323(5910), 79-82. doi: 10.1126/science.1166900.

Moneta, G. B., \& Csikszentmihalyi, M. (1996). The Effect of Perceived Challenges and Skills on the Quality of Subjective Experience. Journal of Personality, 64(2), 275-310. doi: 10.1111/j.1467-6494.1996.tb00512.x.

Pugh, D., Touchie, C., Humphrey-Murto, S., Wood, T.J. (2015). The OSCE progress test measuring clinical skill development over residency training. Medical Teacher, 38(2), 168-73. doi: 10.3109/0142159X.2015.1029895.

Pugh, D. \& Regehr, G. (2016). Taking the sting out of assessment: is there a role for progress testing? Medical Education, 50, 721-729. doi:10.1111/medu.12985.

Salen, K \& Zimmerman, E. (2003). Rules of Play: Game Design Fundamentals. The MIT Press

Scheele, F., Puyenbroek, J. I., Wolf, B., Schutte, M. F., \& Schade, M. I. (2004). Toetsing in de opleiding tot gynaecoloog. Tijdschrift Voor Medisch Onderwijs, 23(1), 40-50. doi: 10.1007/BF03056632.

Sjöblom, M., \& Hamari, J. (2017). Why do people watch others play video games? An empirical study on the motivations of Twitch users. Computers in Human Behavior, 75, 985-996. doi: 10.1016/j.chb.2016.10.019. 
Smith, T., Obrist, M., \& Wright, P. (2013). Live-streaming changes the (video) game. Proceedings of the 11th European Conference on Interactive TV and Video - EuroITV '13. doi: 10.1145/2465958.2465971.

Tinto, V. (1987). Leaving college: rethinking the cause and cures of student attrition. Chicago: University of Chicago Press.

Thoben, A.J.N.M., Leunissen, R.R.M., Jacobs, J.C.G., and Holdrinet, R.S.G. (2006). Het raadplegen van individuele feedback op de voortgangstoets door Nijmeegse studenten geneeskunde, Tijdschrift voor Medisch Onderwijs 2006; 25: 125-33. doi: 10.1007/BF03056730.

Van Goch, M. (2018). Creativity in liberal education before and after study commencement. 4th International Conference on Higher Education Advances (HEAd'18), 1475-1483. doi: 10.4995/HEAd18.2018.8228.

Van Vugt, M., Hogan, R., \& Kaiser, R. B. (2008). Leadership, followership, and evolution: Some lessons from the past. American Psychologist, 63(3), 182-196. doi: 10.1037/0003-066X.63.3.182. doi: 10.1037/0003-066X.63.3.182. 